\title{
The Cytoskeletal Linking Proteins, Moesin and Radixin, Are Upregulated by Platelet-derived Growth Factor, but not Basic Fibroblast Growth Factor in Experimental Mesangial Proliferative Glomerulonephritis
}

\author{
Christian Hugo, ${ }^{\star}$ Claudia Hugo, ${ }^{*}$ Raimund Pichler, ${ }^{\star}$ Katherine Gordon, ${ }^{\star}$ Rodney Schmidt, ${ }^{\ddagger}$ Manuel Amieva, ${ }^{\S}$ \\ William G. Couser, ${ }^{*}$ Heinz Furthmayr, ${ }^{\S}$ and Richard J. Johnson* \\ *Division of Nephrology, Department of Medicine and ${ }^{\ddagger}$ Department of Pathology, University of Washington, Seattle, Washington 98195; \\ and ${ }^{\S}$ Department of Pathology, Stanford University School of Medicine, Stanford, California 94305
}

\begin{abstract}
The expression of the two cytoskeletal linking proteins, moesin and radixin, was examined in experimental mesangial proliferative nephritis in rats (anti-Thy1 model). Moesin and radixin mRNA and protein are constitutively expressed in all cell types of normal rat glomeruli, except podocytes. In the anti-Thy1 model the expression of moesin and radixin was increased in infiltrating macrophages and in activated, $\alpha$-smooth muscle actin-positive mesangial cells and was concentrated in the cellular extensions of mesangial cells in areas of glomerular remodelling. Studies using neutralizing antibodies demonstrated that the increase in moesin and radixin expression by mesangial cells is mediated by PDGF, but not bFGF. The increase in these cytoskeletal proteins appears to be regulated primarily (radixin) or partially (moesin) posttranscriptionally. The data suggest that PDGF mediated upregulation of the cytoskeletal proteins, moesin and radixin, is important for cell migration and other changes that accompany the coordinated restoration of glomerular architecture after injury. (J. Clin. Invest. 1996. 97:2499-2508.) Key words: moesin • radixin • migration • cytoskeleton • glomerulonephritis
\end{abstract}

\section{Introduction}

In glomerulonephritis, glomerular injury may result from antibody deposition alone, local complement activation, or the release of inflammatory mediators from infiltrating or resident cells (1). Despite diverse causes of glomerular injury (immune, hemodynamic, metabolic, toxic), the glomerular response to injury has remarkable similarities involving proliferative, hypertrophic and phenotypic changes in the various cell populations, often with a stimulation of extracellular matrix synthesis (2). For example, in experimental mesangial proliferative nephritis in rats induced by anti-Thy1 antibody, the mesangial

Portions of this work were presented at the American Society of Nephrology annual meeting, Orlando, FL, October 26-29, 1994 (J. Am. Soc. Nephrol. 5:782).

Address correspondence to Christian Hugo, Division of Nephrology, Box 356521, BB-1265 Health Sciences, University of WA Medical Center, Seattle, WA 98195. Phone: 206-543-3792; FAX: 206-6858661.

Received for publication 12 October 1995 and accepted in revised form 1 March 1996.

J. Clin. Invest.

(C) The American Society for Clinical Investigation, Inc.

0021-9738/96/06/2499/10 \$2.00

Volume 97, Number 11, June 1996, 2499-2508 cell $(\mathrm{MC})^{1}$ proliferates, undergoes a transient phenotypic transformation to a "myofibroblast" in which it expresses de novo the muscle actin isoform, $\alpha$-smooth muscle actin $(\alpha$-sm actin), and secretes excess matrix (2). Similar changes have been documented in human glomerular disease (3). The de novo expression of $\alpha$-sm actin may be required for MC contractility and cell migration that are associated with matrix expansion and subsequent remodelling within glomeruli (4).

Cell migration is critically important to many basic biological processes, such as embryonic development, wound healing and inflammation. In the anti-Thy1 model most of the MC are killed during the initial complement-dependent mesangiolysis (4). It is not known if the repopulation by MC involves proliferation of the remaining, sublethally injured $\mathrm{MC}$ or whether there is also migration of MC precursors ("mesangioblasts") into glomeruli. Regardless, the proliferating MC, which initially are often localized in areas of high cell density forming cell "nests" (clusters) or in areas of low cell density such as microaneurysms, must migrate to some extent as they are found eventually in characteristic location in association with reconstitution of a normal glomerular architecture.

Despite the likelihood that cell migration is an important feature in glomerulonephritis, very little evidence has been provided to date. Barnes et al. (5) reported that desmin positive MC may migrate into microaneurysms in the Habu snake venom model, based on repeated biopsies in individual animals. It is also known that MC migrate in culture in response to growth factors such as PDGF (6), fibronectin (7), and thrombospondin (8).

To migrate, cells change shape and develop cell processes such as filopodia, lamellipodia, retraction fibers, and microspikes (9). These cell protrusions are ubiquitously present in moving or activated cells and presumably provide specialized surfaces for adhesive and signaling interactions. Cell movement is also associated with the formation of new actin filaments localized preferentially at the leading edge (10). This actin polymerization may generate the force to push the membrane forward, while myosin contraction at the rear of the cell causes a graded retraction of the cell margin. Changes in actin dynamics are dependent upon changes in actin binding proteins and vice versa. Recently it has been reported that moesin (11) and radixin (12) are important plasma membrane-cytoskeleton linking proteins that are preferentially localized in filopodia during cell activation/locomotion and bind to actin filaments $(13,14)$. Moesin and radixin have been found to be critical for cell-cell adhesion and microvilli formation (15). Al-

1. Abbreviations used in this paper: $\mathrm{bFGF}$, basic fibroblast growth factor; GEC, glomerular epithelial cell; GEN, glomerular endothelial cell; ISH, in situ hybridization; MC, mesangial cell; PCNA, proliferating cell nuclear antigen; sm, smooth muscle. 
though constitutively expressed in many cell types, a redistribution of moesin to filopodia or other microdomains occurs with cell activation/migration in vitro $(13,16)$.

In this paper, we examine the expression of these cytoskeletal proteins and their mRNA in normal kidney and in rats with mesangial proliferative glomerulonephritis (anti-Thy1 model). A dramatically increased expression of moesin and radixin by activated, $\alpha$-smooth muscle actin-positive MC can be demonstrated with mesangial cell injury and appears to be dependent on PDGF, but not bFGF. In areas of perturbed glomerular architecture increased expression of moesin and radixin is concentrated in cell margins and cell extensions. Moesin and radixin may thus be important for cell migration and remodelling that occurs in glomerular disease.

\section{Methods}

Experimental design. Expression of moesin and radixin was analyzed in cultured rat MC, glomerular epithelial cells (GEC), and glomerular endothelial cells (GEN), and in a rat model resembling human IgA nephropathy induced by an antibody to the Thy1 antigen on MC (anti-Thy1 disease).

At various time points after induction of the anti-Thy1 model, renal biopsies were obtained and immunostained for moesin, radixin, $\alpha$-smooth muscle actin, and the proliferating cell nuclear antigen (PCNA). Glomerular expression of moesin, radixin, and $\alpha$-actin was graded semiquantitatively in a blinded fashion using a score from 0 to 4. Moesin and radixin staining was also assessed by quantitative image analysis using Optimas 4.0 image analysis software (Optimas Corporation, Bothell, WA). To identify the cells expressing moesin and radixin, tissue was double stained for moesin or radixin using cell specific markers for proliferating cells (PCNA), macrophages (ED-1), GEN (RECA-1) (17), and activated MC ( $\alpha$-sm actin) (4). In addition to immunostaining, the glomerular expression of moesin and radixin was studied by immunoblotting of isolated glomerular protein lysates and by in situ hybridization using antisense and sense ${ }^{35}$ S-labeled cRNA probes.

Studies were also performed to determine if these cytoskeletal proteins are regulated by PDGF or bFGF. This included examining renal biopsy tissue from previous studies in which rats with anti-Thy1 disease had been treated with neutralizing antibodies to PDGF (18) or bFGF (19), as well as renal tissue from normal rats or rats with "subnephritogenic" anti-Thy1 disease that had been administered PDGF or bFGF intravenously (20).

Glomerular cell culture. Rat MC and GEC were prepared from normal glomeruli, characterized and maintained as described previously $(21,22)$. GEN were obtained from Dr. Stephen Adler (NY Medical College, Westchester Medical Center, Valhalla, NY) and have been characterized previously (23).

In vivo disease models. Experimental mesangial proliferative nephritis was induced in 180-220-gram male Wistar rats (Simonsen Laboratories, Gilroy, CA) by intravenous injection of goat anti-rat thymocyte plasma ( $0.4 \mathrm{cc} / 100$ gram body weight) (24). Rats were sacrificed and renal biopsies and total glomerular protein obtained at days $2,5,7$, and 14 ( $n=6-9$ per group). Six additional rats were also complement-depleted for $5 \mathrm{~d}$ with cobra venom factor (CVF) (Diamedics Corp., Miami, FL). In these rats, C3 levels were measured by radial immunodiffusion (24) and values of $<10 \%$ were maintained throughout the study period. Six normal rats (day 0) served as controls.

Moesin and radixin expression was also examined in normal and low dose anti-Thy1 rats that had received a seven day intravenous infusion of either PDGF-BB and/or bFGF as described previously (20). Rat tissue was obtained 2, 4, and $7 \mathrm{~d}$ after starting the cytokine infusion.

Moesin and radixin expression was investigated in rats with antiThy1 nephritis, which had also received neutralizing anti-PDGF antibody or control IgG as described before (18).
The effect of neutralizing anti-bFGF antibody on moesin and radixin expression in the anti-Thy1 model was investigated. Goat antihuman recombinant bFGF IgG or control goat IgG (gift of M. Reidy, University of Washington, Seattle, WA) (25) was given (30 mg i.p. and $30 \mathrm{mg}$ i.v.) to male Wistar rats (170-190 grams) $30 \mathrm{~min}$ before injection of anti-Thy1 plasma and renal biopsies were obtained at days 2, 4, and 7 (19).

Renal morphology and immunohistochemistry. Renal biopsies were fixed in methyl Carnoy's solution and embedded in paraffin (4). Indirect immunoperoxidase and immunofluorescent staining of $4-\mu \mathrm{m} \mathrm{sec}-$ tions was performed as described previously (4) using the following antibodies to moesin and radixin (Table $\mathrm{I}$ ). These antibodies include $\mathrm{mAb} 38 / 87$, a murine monoclonal $\mathrm{IgG}_{1}$ antibody, raised against calf moesin $(13,26)$; (pAsMoER) and (pAsR), rabbit polyclonal antisera (pAs) to purified human moesin and a bacterially produced fragment of human radixin (13); (pAbMo), an affinity purified moesin-specific antibody, after adsorption (of pAsMoER) with recombinant human radixin and ezrin $(13,14)$. In addition, tissue was stained with murine IgM mAb against the proliferating cell nuclear antigen (PCNA) (19A2, Coulter Immunology, Hialeah, FL), murine $\operatorname{IgG}_{1}$ mAb, ED-1, to a cytoplasmic antigen present in monocytes, macrophages and dendritic cells (Bioproducts for Science, Inc., Indianapolis, IN), murine $\mathrm{IgG}_{1} \mathrm{mAb}$ against the endothelial antigen RECA-1 (17), a murine $\mathrm{IgG}_{1} \mathrm{mAb}$ against SPARC (Haematologic Technologies Inc., Essex Jct., VT) (27), a murine $\operatorname{IgG}_{2} \mathrm{mAb}$ against $\alpha$-smooth muscle actin (28) (Sigma Chemical Co., St. Louis, MO). Negative controls for immunostaining included either deleting the primary antibody or substitution of the primary antibody with equivalent concentrations of an irrelevant murine monoclonal antibody or preimmune rabbit IgG. For each biopsy, 20-70 glomerular cross-sections were evaluated in a blinded fashion. Glomerular expression of moesin, radixin, and $\alpha$-sm actin was graded semiquantitatively (29) and reflected changes in the area and intensity of mesangial staining: 0 : very weak or absent staining; $1+$ : weak staining with $<25 \%$ of the glomerular tuft showing focally increased staining; $2+: 25-49 \%$ of the glomerular tuft with focally increased staining; $3+: 50-75 \%$ of the glomerular tuft demonstrating increased staining; and $4+:>75 \%$ of the glomerular tuft stained strongly. In addition to the semiquantitative visual scoring system, moesin and radixin staining was assessed by quantitative image analysis using Optimas 4.0 image analysis software. Glomerular tufts were outlined, the level of background staining determined, and the (total and above background) intensity as well as the area of positive staining and outlined glomerular area were assessed by the computer program, measuring the integrated logarithm of the inverse gray value (ILIGV), which is proportional to the total amount of absorbing material in the light path. This system allowed us to measure quantitatively the intensity and percentage area of positive staining for each glomerulus.

In addition, in order to improve resolution of the staining pattern of moesin, indirect immunofluorescent staining with the moesin specific antibody (pAbMo) was also performed on paraffin embedded semithin $1-\mu \mathrm{m}$ sections.

Immunohistochemical double staining. To determine the cell types expressing these cytoskeletal proteins, double immunostaining with moesin-specific antibodies and cell specific markers was performed using an indirect immunofluorescent technique. For constitutive glomerular endothelial (GEN) or podocyte expression in normal rats, affinity purified moesin-antibodies were incubated together with antibodies to RECA-1(for GEN) or SPARC (which is predominantly expressed by podocytes in the normal rat glomerulus) (27) overnight at $4^{\circ} \mathrm{C}$, followed sequentially by Texas red-conjugated goat anti-rabbit $\mathrm{IgG}$, biotinylated rabbit anti-mouse $\mathrm{IgG}_{1}$ (Zymed, San Francisco, CA), and FITC-conjugated streptavidin D. To determine whether activated MCs or infiltrating macrophages specifically express these cytoskeletal proteins, moesin specific antibodies were incubated with $\alpha$-sm actin or ED-1 antibodies, respectively, and the equivalent protocol followed. Double labeling of moesin or radixin with proliferating cells (PCNA) was performed according to a previously described 
Table I. Specificity of Moesin and Radixin Antibodies in Rat Tissue or Cells

\begin{tabular}{ccccc}
\hline Antibody & pAsR & mAb38/87 & pAsMoER & pAsMo \\
\hline Moesin staining (rat) & - & - & + & + \\
Radixin staining (rat) & + & + & + & - \\
\hline
\end{tabular}

protocol (30) using an immunoperoxidase staining technique. The controls for all double staining procedures consisted of replacing either one of the primary antibodies with an irrelevant mouse monoclonal antibody or preimmune rabbit IgG.

Immunoblotting of moesin and radixin and specificity of the antibodies. Immunoblotting was performed as described previously (30), but $7-10 \%$ separating SDS-PAGE gels (31) were used and $5 \mu \mathrm{g}$ of total glomerular protein was loaded per lane. Amieva and Furthmayr (13) have extensively characterized the antibodies used in this study. The radixin antiserum (pAsR) and monoclonal antibodies 38/87 (mAb 38/87) react specifically with the $80-\mathrm{kD}$ band of radixin. The polyclonal moesin antisera (pAsMoER) react with both bands for moesin $(78 \mathrm{kD})$ and radixin $(80 \mathrm{kD})$, while the affinity purified moesin antibodies (pAbMo) only recognize moesin (13) (Table I). Western blot analysis of whole glomerular lysates of normal and diseased rats confirmed the specificities of these reagents in rat tissue or cells (Table I). Successful absorption of the moesin (pAbMo)-specific immunostaining could only be achieved using recombinant moesin, but not using recombinant radixin. Radixin specific staining (pAsR, $\mathrm{mAb} 38 / 87$ ) was absorbable with recombinant radixin, but not with moesin (not shown). These results clearly demonstrate the specificity of these antibodies on Western blot and tissue sections.
Preparation of glomerular RNA and Northern analysis. Total RNA was extracted from cultured MC and GEC with RNAzol B (Cinna/ Biotecx Laboratories, Friendswood, TX) followed by $\mathrm{LiCl}$ precipitation (20). $10 \mu \mathrm{g}$ of cultured cell RNA per lane were electrophoresed through a $3 \%$ formaldehyde, $1 \%$ agarose gel and transferred to a nylon membrane (Hybond $\mathrm{N}^{+}$, Amersham Corp., Arlington Heights, IL) as previously described (4). A 1.059-kb SmaI fragment of the pig moesin cDNA clone (12) and a 1.325-kb EcoRI fragment of the pig radixin cDNA clone (12) were isolated, purified with the SpinBindsystem (FMC Corp., Rockland, ME), and radiolabeled with $\left[{ }^{32} \mathrm{P}\right]$ dCTP $(10 \mu \mathrm{Ci} / \mathrm{ml})$ (New England Nuclear, Boston, MA) by random primer extension. Membranes were prehybridized for $20 \mathrm{~min}$, hybridized with $2 \times 10^{6} \mathrm{cpm}$ probe $/ \mathrm{ml}$ for $1-2 \mathrm{~h}$ at $68^{\circ} \mathrm{C}$ in Quickhyb solution (Stratagene, La Jolla, CA) and washed with $0.1 \times$ SSPE, $0.1 \%$ SDS twice for $30 \mathrm{~min}$ at $55^{\circ} \mathrm{C}$. All Northern blots were repeated at least three times with RNA from different tissue culture experiments.

In situ hybridization for moesin and radixin. Moesin and radixin mRNA was detected by in situ hybridization on formalin-fixed tissue using ${ }^{35} \mathrm{~S}$-labeled anti-sense and sense-cRNA probes to pig moesin or radixin cDNA. Hybridization was performed using a protocol of Wilcox et al. (32). After developing, sections were counterstained with toluidine blue or hematoxylin/eosin, dehydrated and coverslipped. Quantitation of in situ hybridization was done under brightfield and darkfield illumination evaluating 20 glomerular cross sections in a blinded fashion. Glomerular mRNA expression was graded as follows: 1. glomerular mRNA signal was less than tubular mRNA; 2. glomerular and tubular mRNA level were in the same range; and 3. glomerular mRNA expression was greater than tubular mRNA. To verify these results from the semiquantitative scoring system (considering possible changes in tubular mRNA) the average number of silver grains per glomerulus at the peak of expression in disease and in the control group was also counted.
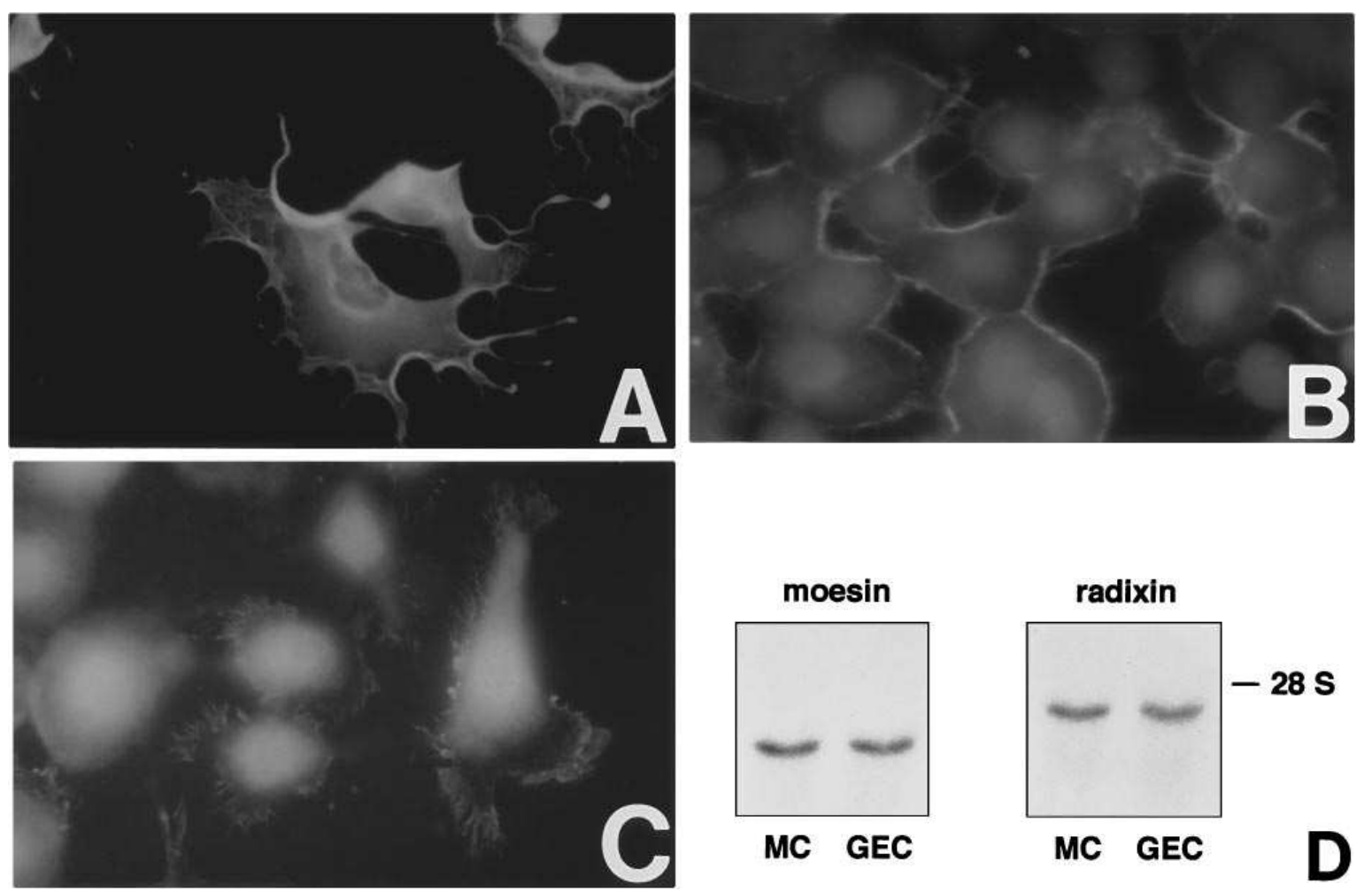

Figure 1. Expression of moesin and radixin by cultured MC, visceral GEC and GEN. Immunostaining for moesin/radixin in MC ( $A$ ), visceral GEC $(B)$, and GEN $(C)$ using the pAsMoER. In nonconfluent MC and GEN ( $A$ and $C$ ), staining was cytoplasmic and localized to perinuclear areas, cellular extensions such as filopodia, and to a lesser degree to the plasma membrane. Cultured visceral (cobblestone) GEC $(B)$ demonstrated predominant plasma membrane and filopodial and fainter perinuclear staining. Northern blot analysis $(D)$ of total RNA from cultured rat $\mathrm{MC}$ and GEC demonstrates transcripts for both moesin and radixin mRNA. 
Statistical analysis. All values are expressed as mean \pm SD. Statistical significance (defined as $P<0.05$ ) was evaluated using the Student's $t$ test or one way analysis of variance with modified $t$ test was performed using the Bonferoni method.

\section{Results}

Expression of moesin and radixin protein and $m R N A$ in cultured $M C, G E C$, and $G E N$. Moesin and radixin were expressed by all three glomerular cell types in culture. The immunostaining pattern of MC, GEC, and GEN for both proteins (using pAsR, mAb 38/87, pAsMoER, and pAbMo) was very similar and dependent on the degree of cell confluency. In nonconfluent MC and GEN, staining was cytoplasmic and localized to perinuclear areas, cellular extensions such as filopodia, and to a lesser degree to the plasma membrane (Fig. 1, $A$ and $C$ ). Cultured GEC, which usually grow in close association to each other (cobblestone), demonstrated predominant plasma membrane and filopodial and fainter perinuclear staining (Fig. $1 B$ ). In confluent MC and GEN staining for moesin and radixin changed to a very similar pattern as described above for GEC (data not shown). Northern blot analysis of MC and GEC RNA confirmed the presence of moesin and radixin mRNA (Fig. 1D).

Expression of moesin and radixin protein in the normal rat kidney. On rat kidney sections, the staining pattern with all of the moesin or radixin antibodies (pAsMoER, pAbMo, pAsR, and $\mathrm{mAb38/87)}$ was indistinguishable. In the normal rat glomerulus, moesin and radixin are expressed primarily by GEN, and to a lesser extent by MC and parietal GEC (Fig. $2 A$ and see Fig. $7 A$ ). Staining of podocytes could not be detected. Furthermore, double staining with an antibody against SPARC, which predominantly labels podocytes in the normal rat glomerulus (27), and moesin (or radixin) did not show any colocalization. The staining pattern was also confirmed by double labeling with a cell specific marker for GEN, using the antibody RECA-1 (data not shown). Moesin and radixin are also expressed in the brush border microvilli of proximal tubular epithelial cells (Fig. 2) and to a lesser extent by some distal tubules and collecting ducts. Moesin and radixin are also present in the endothelial lining of capillaries and larger blood vessels in the kidney (not shown).

Moesin and radixin are increased in mesangial areas during mesangial proliferative nephritis (anti-Thy1 model). The antiThy1 model is characterized by an initial complement-dependent mesangial injury with platelet and macrophage infiltration on days 1 and 2, a PDGF- and bFGF-dependent MC proliferation between days 2 and 7 (peaking at day 5, Table II), a mesangial matrix expansion (maximal between days 7 and 14) (4) and a phenotypic change of MCs to a "myofibroblast" cell type between days 3 and 14 (maximal at day 7, Table II). At day 2, individual mononuclear cells, as well as cells within and near the juxtaglomerular (JG) apparatus, stained strongly positive for moesin and radixin (Fig. $2 \mathrm{~B}$ ). By day 5 , moesin and radixin staining was dramatically increased in a typical mesangial pattern and peaked at day 7 of anti-Thy1 disease (Fig. 2 C). By day 14 , the staining pattern was still markedly elevated, but had returned towards normal (not shown). Assessment of moesin and radixin staining by quantitative image analysis using Optimas 4.0 image analysis software confirmed the results of visual scoring and demonstrated that the increase in moesin and radixin involved both an increase in intensity (blackness) and percentage area of glomerular staining (independent from
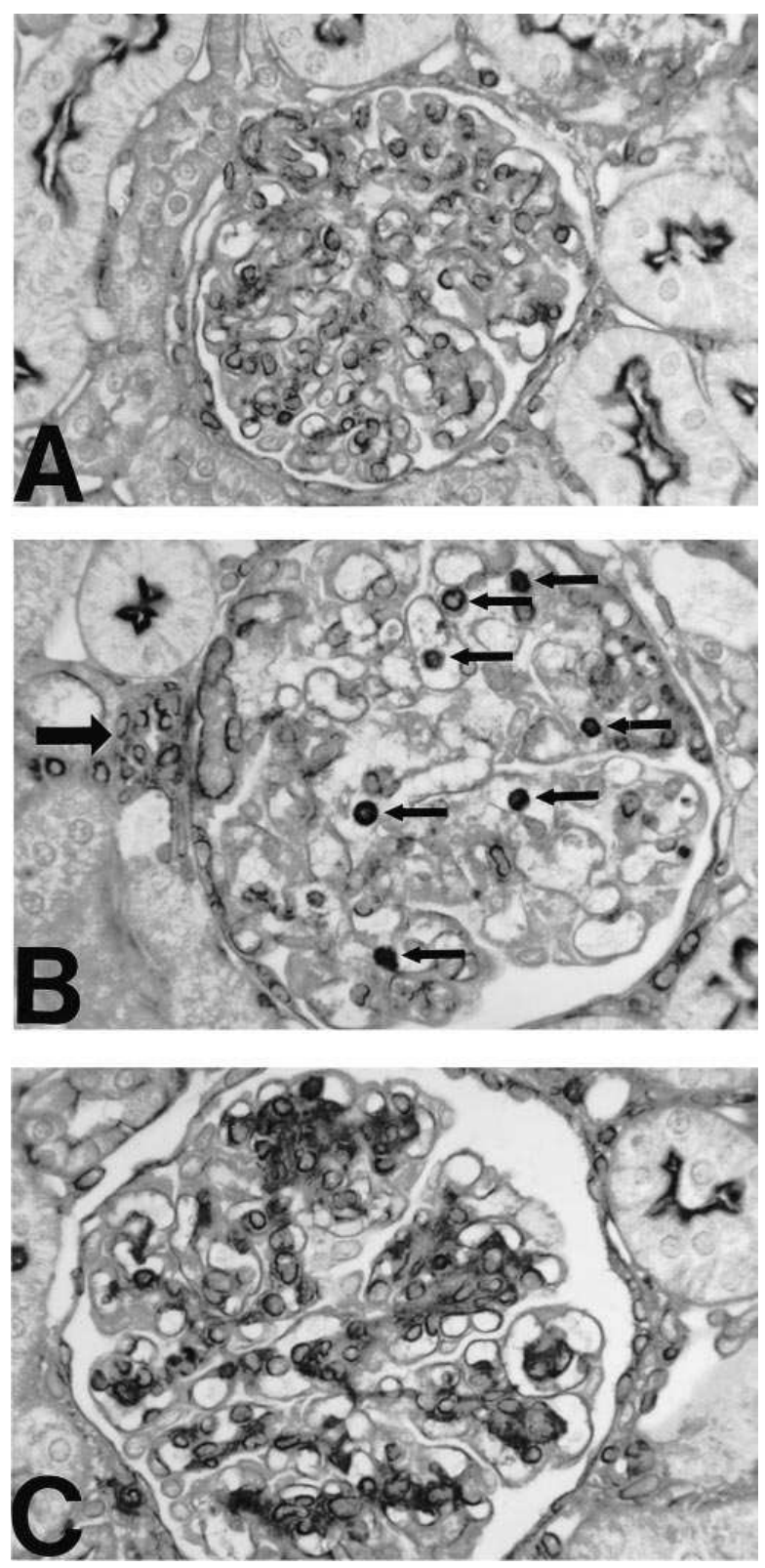

Figure 2. Localization of moesin and radixin in normal and diseased glomeruli. In glomeruli from normal rats $(A)$, moesin/radixin is expressed primarily by GEN, and to a lesser degree by MC and parietal GEC, but not by podocytes as noted by immunostaining using the pAsMoER antibody. At day 2 of anti-Thy1 disease moesin/radixinpositive mononuclear cells (macrophages by double labeling, thin arrows) and cells of the juxtaglomerular apparatus (thick arrow) can be identified $(B)$. At day 7 maximal moesin/radixin protein expression can be identified in a typical mesangial pattern $(C)$. When specific antibodies (pAbMo, pAsR, mAb 38/87) were used, the staining pattern for radixin and moesin in glomeruli was indistinguishable from each other (not shown).

hypertrophy) during disease (Fig. 3, Table II). Moesin and radixin expression peaked at day 7, two days after the peak of MC proliferation (at day 5, assessed by PCNA staining) (Table II), at a time when MC proliferation had already returned towards normal. Moesin/radixin expression paralleled the de novo expression of $\alpha$-sm-actin, another cytoskeletal protein, that has been reported to be a marker for activated MC (4) 
Table II. Moesin, Radixin, PCNA, and $\alpha$-sm Actin Immunostaining and Glomerular Size during Anti-Thy1 Nephritis Using the Quantitative Image Analysis, the Semiquantitative Visual Scoring System (0-4) or Counting of Positive Cells per Glomerular Cross Section

\begin{tabular}{|c|c|c|c|c|c|c|}
\hline \multicolumn{2}{|c|}{ anti-Thy 1 model } & \multirow{2}{*}{$\begin{array}{c}\text { day } 0 \\
1.6 \pm 0.001\end{array}$} & \multirow{2}{*}{$\begin{array}{c}\text { day } 2 \\
1.8 \pm 0.001\end{array}$} & \multirow{2}{*}{$\begin{array}{c}\text { day } 5 \\
9.4 \pm 0.004\end{array}$} & \multirow{2}{*}{$\frac{\text { day } 7}{14.6 \pm 0.005}$} & \multirow{2}{*}{$\begin{array}{c}\text { day } 14 \\
5.9 \pm 0.003\end{array}$} \\
\hline & Intensity & & & & & \\
\hline Moesin & $\%$ Area & $6.0 \pm 0.02$ & $4.4 \pm 0.002$ & $21.5 \pm 0.002$ & $34.4 \pm 0.10$ & $14.6 \pm 0.006$ \\
\hline \multirow[t]{2}{*}{ (pAsMo) } & Visual Score & $0.29 \pm 0.02$ & $0.36 \pm 0.01$ & $2.27 \pm 0.02$ & $2.75 \pm 0.16$ & $1.4 \pm 0.07$ \\
\hline & Intensity & $0.34 \pm 0.01$ & $0.16 \pm 0.002$ & $2.66 \pm 0.01$ & $5.03 \pm 0.02$ & $1.36 \pm 0.01$ \\
\hline Radixin & $\%$ Area & $2.1 \pm 0.02$ & $0.8 \pm 0.01$ & $11.0 \pm 0.04$ & $27.9 \pm 0.09$ & $7.4 \pm 0.06$ \\
\hline (mAb 38/87) & Visual Score & $0.29 \pm 0.02$ & $0.22 \pm 0.01$ & $2.31 \pm 0.01$ & $2.84 \pm 0.01$ & $1.36 \pm 0.04$ \\
\hline PCNA & cells/glom. & $0.24 \pm 0.02$ & $4.0 \pm 0.15$ & $12.78 \pm 0.42$ & $5.9 \pm 0.06$ & $0.65 \pm 0.02$ \\
\hline$\alpha$-Actin & Visual Score & $0 \pm 0$ & $0.44 \pm 0.02$ & $2.1 \pm 0.05$ & $2.55 \pm 0.02$ & $1.73 \pm 0.07$ \\
\hline Glom. Size & $\mathrm{mm}^{2} \times 10^{-2}$ & $0.72 \pm 0.006$ & $0.98 \pm 0.002$ & $1.23 \pm 0.001$ & $1.20 \pm 0.002$ & $1.15 \pm 0.002$ \\
\hline
\end{tabular}

All the data on days 5 and 7 in regard to moesin, radixin, PCNA, $\alpha$-sm actin immunostaining and glomerular size are significant $(P<0.01)$.

Data are mean \pm SE.

(Table II). Statistical comparison of glomerular moesin staining with $\alpha$-sm-actin expression in individual animals revealed a strong correlation with a regression (r) coefficient of 0.96 (Fig. $4, P \leq 0.001)$. Complement depletion initiated prior to disease induction normalized all histological changes as well as the increased moesin or radixin staining at day 5 (not shown).

The marked increase in radixin and moesin protein during anti-Thy1 disease in comparison to normal controls was confirmed by Western blot analysis of the total cell lysate of isolated glomeruli (Fig. 5).

Moesin $m R N A$, but not radixin $m R N A$ is increased during anti-Thy1 disease. In situ hybridization (ISH) of tissue sections from two different experiments was performed to determine whether moesin and radixin mRNA were modulated during the course of anti-Thy1 disease. As shown in Fig. 6, glomerular moesin mRNA was increased during the time

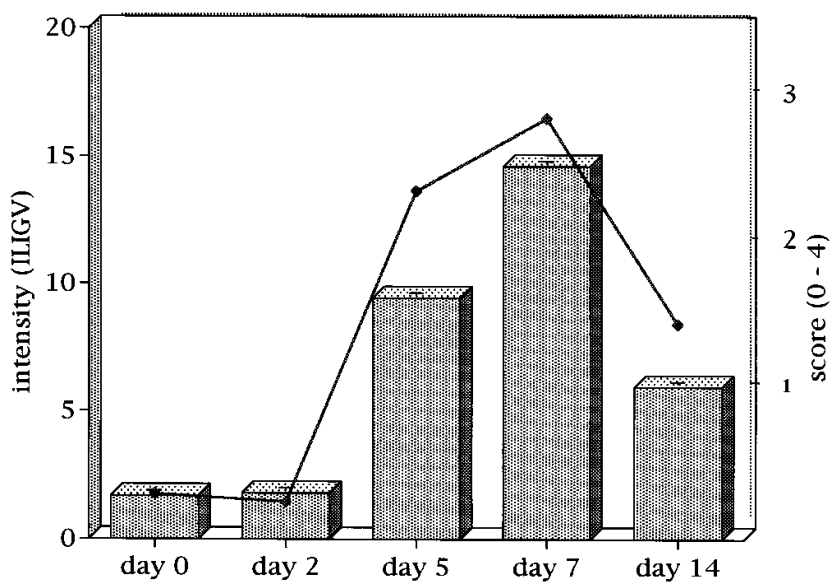

Figure 3. Quantitation of moesin protein expression in anti-Thy1 disease. Moesin (using pAbMo) immunostaining was assessed during the time course of anti-Thy1 disease using a semiquantitative scoring system from 0 to 4 as well as the quantitative Optimas 4.0 image analysis software as described in Methods. The graph demonstrates the increase in staining intensity (columns, measures the integrated logarithm of the inverse gray value, ILIGV, which is proportional to the total amount of absorbing material in the light path) for moesin during disease compared to the visual scoring system (line). Data are mean \pm SE. $* P<0.01$ vs. day 0 . course of disease. This increase in moesin mRNA expression preceded the increase in moesin protein. While in normal rats glomerular moesin mRNA was lower than its tubular expression (Fig. 6, $A$ and $B$ ), moesin mRNA was increased at day 2, peaked at day 3-4 when glomerular expression exceeded tubular mRNA levels (Fig. 6, $C$ and $D$ ), and returned to normal at day 14 (Table III). Quantitation of the in situ hybridization data by grain counting (Table III) revealed a three- to fourfold increase of moesin mRNA expression per glomerular cell when corrected for the $\sim$ twofold increase in total cell number at day 3. In contrast, glomerular radixin mRNA distribution was identical to moesin mRNA, but glomerular mRNA levels remained below tubular levels during the entire time course of anti-Thy1 disease, and no significant changes were detected (Table III).

Identification of cells expressing increased levels of moesin and radixin in anti-Thy1 disease. By double immunostaining, the great majority of the $\alpha$-sm actin positive, activated MCs ("myofibroblasts") were expressing increased amounts of moesin and radixin (Fig. $7 b$ ). Double labeling using antibodies

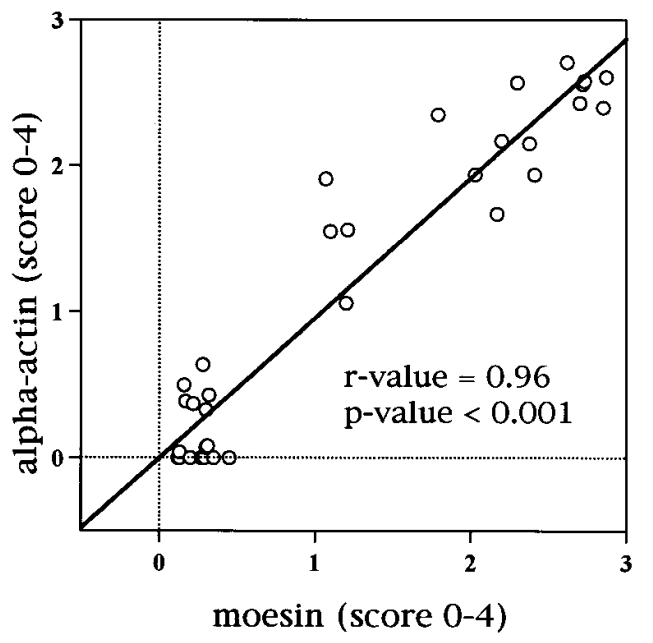

Figure 4. Correlation of glomerular moesin/radixin expression with $\alpha$-sm-actin expression by activated MC. A linear regression analysis of moesin/radixin and $\alpha$-sm-actin staining in individual animals reveals a very high regression coefficient of $0.96(P \leq 0.001)$. 


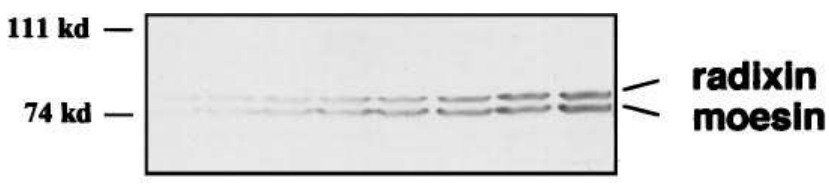

day 0 day 2 day 5 day 7

Figure 5. Expression of moesin and radixin by Western blot analysis of glomerular lysates in the anti-Thy1 model. Western blot analysis of glomerular lysates during the time course of anti-Thy1 disease (days $0,2,5$, and 7 in duplicate, from left to right) using the polyclonal rabbit serum raised against purified moesin (pAsMoER) demonstrates a striking increase in both moesin and radixin during disease (peaking at day 7).

to ED-1 and to moesin or radixin also identified infiltrating macrophages as a source of these cytoskeletal proteins (not shown). Double labeling using antibodies to PCNA and to moesin or radixin revealed that many proliferating cells (PCNA-positive) and cells with mitotic figures were strongly positive for these cytoskeletal proteins. However, the increased expression of moesin/radixin was not tightly linked to proliferation, since moesin and radixin levels remained high after cell proliferation had subsided (days 7-4).

Moesin and radixin expression are concentrated in areas of glomerular remodeling in anti-Thy1 disease. In anti-Thy1 dis- ease $\sim 7-8 \%$ of the glomeruli develop microaneurysms at days 5 to 7 , which heal completely within several weeks. In the healing microaneurysms and other areas of glomerular remodelling, the regenerating glomerular cells (mainly MCs by double labeling, but also GEN and possibly parietal GEC) strongly expressed moesin/radixin (Fig. 7c). Although not easily appreciated at the light-microscopic level (of 4- $\mu$ m sections), the staining pattern was frequently suggestive for localization to cellular extensions (Fig. $7 \mathrm{c}$ ). Fluorescent moesin antibody staining of $1 \mu \mathrm{m}$ sections in areas of glomerular remodelling confirmed localization to cell extensions (Fig. $7 d$ ) and filopodia (Fig. $7 e$ ). Double staining revealed that, while moesin was frequently found in cell extensions of $\alpha$-sm actin positive MC, $\alpha$-sm actin expression in the same cells did not always colocalize (Fig. $7 f$ ).

Glomerular moesin and radixin expression is induced by $P D G F$, but not bFGF in vivo. Infusion of PDGF-BB in normal rats induced glomerular hypercellularity, primarily due to MC proliferation, while bFGF was without effect (20). Staining of these tissues for moesin revealed, that PDGF but not bFGF significantly stimulated moesin expression (Fig. $8 \mathrm{~A}$ ), while the combined administration of bFGF and PDGF did not have any additive effect.

The application of a low "subnephritogenic" dose of antiThy1 antibody, which by itself did not cause any histological changes, was able to enhance the proliferative effect of PDGF or bFGF infusion in rats (20). Despite the effect of bFGF on
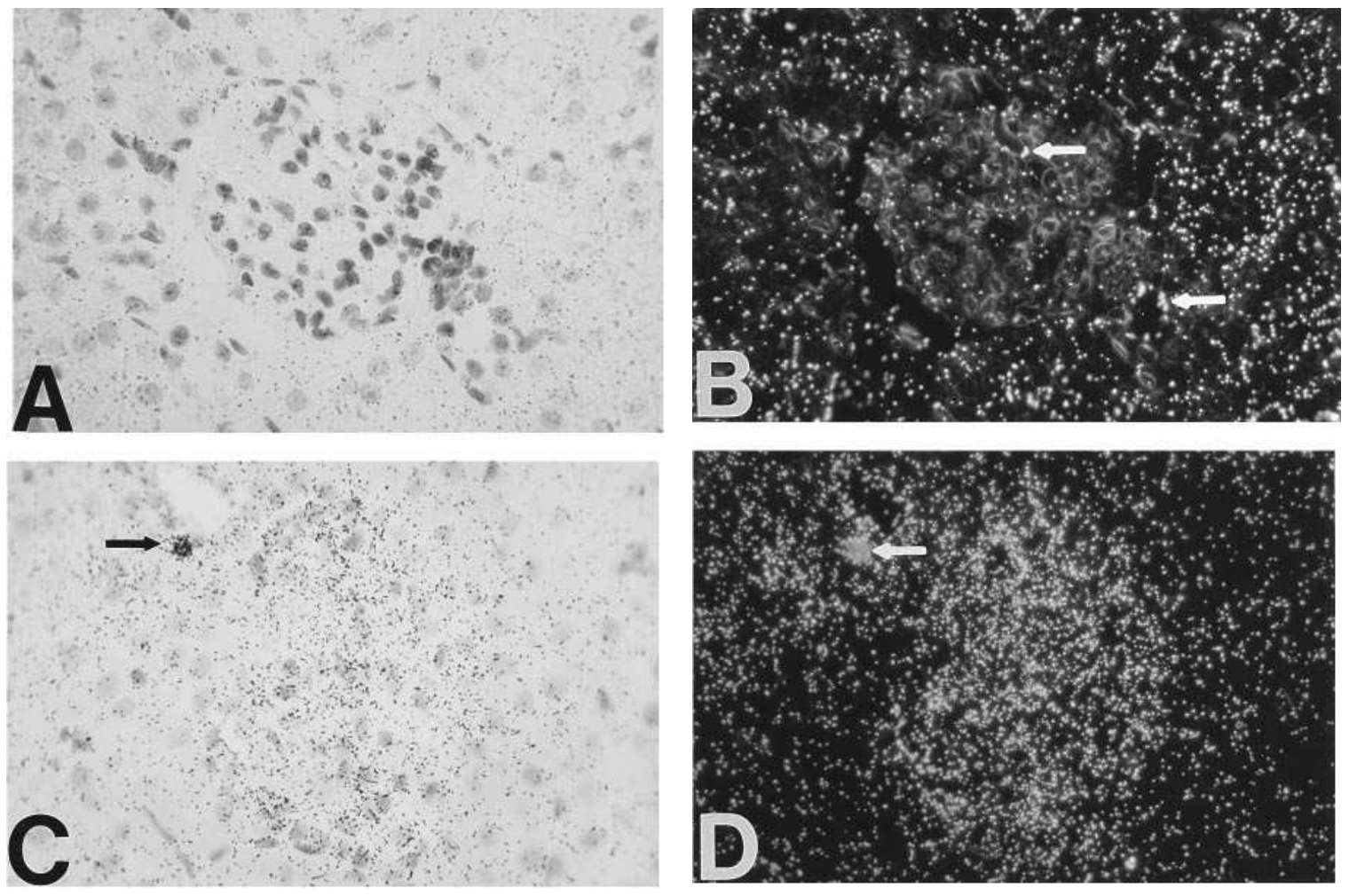

Figure 6. Expression of moesin mRNA of rat glomeruli with anti-Thy1 disease by in situ hybridization. Positive hybridization is indicated by dark grains in the brightfield (left, $A$ and $C$ ) and by white grains in the darkfield (right, $B$ and $D$ ) photomicrographs. In normal rats (day 0 ), glomerular moesin mRNA expression $(A$ and $B)$ is lower than its tubular level. During disease, moesin mRNA peaks at day $3(C$ and $D)$, when glomerular expression clearly exceeds tubular mRNA levels. The arrows in $B$ point to labeling of endothelial cells in glomerular capillaries and the afferent arteriole. In $C$ and $D$, a strongly labeled cell (possibly a macrophage, see double labeling) is marked. Moesin mRNA was increased during disease, while no significant changes were detected for radixin mRNA. 
Table III. Quantification of In Situ Hybridization for Moesin and Radixin mRNA during anti-Thy1 Disease Using a Visual Scoring System (0-3) and/or Grain Counting

\begin{tabular}{|c|c|c|c|c|c|c|c|}
\hline Anti-Thy1 & day 0 & day 2 & day 3 & day 4 & day 5 & day 7 & day 14 \\
\hline Moesin (score 0-3) & $1.0 \pm 0$ & $1.4 \pm 0.1$ & $2.6 \pm 0.1 *$ & $2.2 \pm 0.1 *$ & $1.9 \pm 0.1^{*}$ & $1.5 \pm 0.1$ & $1.2 \pm 0.1$ \\
\hline Grain counts per 20 glom. & $3368 \pm 262$ & & $22135 \pm 1607^{*}$ & & & & \\
\hline Radixin (score $0-3$ ) & $1.0 \pm 0$ & $1.0 \pm 0$ & $1.0 \pm 0$ & $1.0 \pm 0$ & $1.0 \pm 0$ & $1.0 \pm 0$ & $1.0 \pm 0$ \\
\hline Grain counts per 20 glom. & $3120 \pm 276$ & & $4572 \pm 606$ & & & & \\
\hline
\end{tabular}

Data are mean \pm SE, ${ }^{*} P(t$ test $) \leq 0.001$.
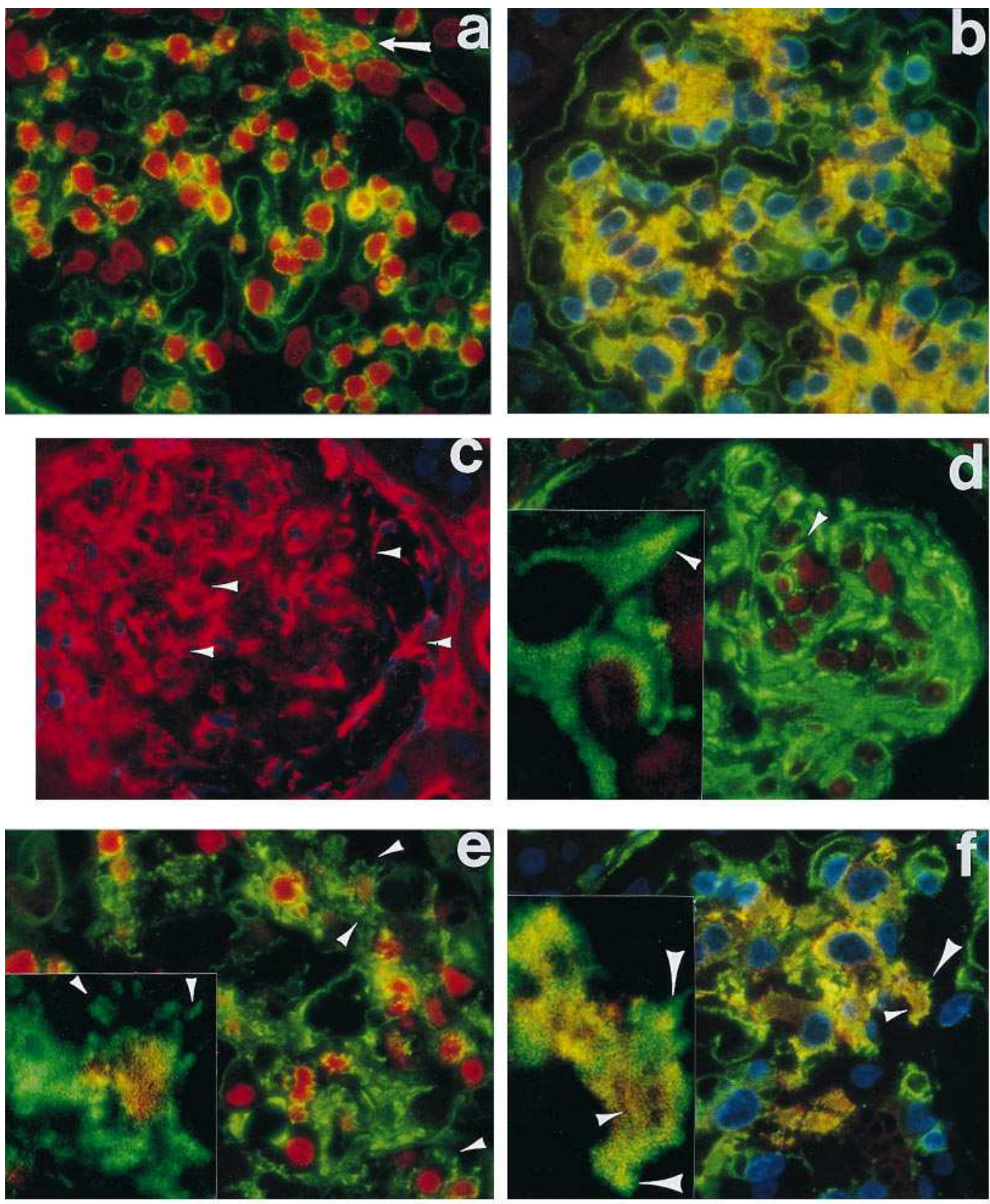

Figure 7. Expression of moesin in normal glomeruli (a), in cell extensions in areas of glomerular remodelling during anti-Thy1 disease $(c-f)$, and colocalization of moesin and $\alpha$-sm actin in activated MC in vivo $(b$ and $f)$. Glomerular $1 \mu \mathrm{m}(a, b, d, e$, and $f$ ) or $4-\mu \mathrm{m}$ (c) sections of day 5 of anti-Thy1 disease were labeled with moesin specific (pAsMo) $(a-f)$ or moesin/radixin specific (pAsMoER) $(c)$ and $\alpha$-sm actin ( $b$ and $f$ ) antibodies using an indirect immunofluorescent technique. All pictures show original images photographed from a Leitz microscope $(\times 1000$, except $c$, $\times 600$ ), while the insets of $d-f$ are computerized magnifications of certain areas of the same images (using Adobe Photoshop ${ }^{\mathrm{TM}}$ 3.0.5, Adobe Systems, Pantone). $a$ demonstrates moesin staining (FITC-green) of juxtaglomerular (arrow), endothelial, mesangial, and parietal epithelial cells in normal glomeruli (Propidium Iodide as nuclear counterstain in red). Double staining for moesin in green (FITC-labeled) and $\alpha$-sm actin in red (Texas red-labeled) with nuclear counterstaining with DAPI (blue) in a glomerulus at day 7 of anti-Thy1 disease demonstrates that the majority of $\alpha$-sm actin positive MC have increased expression of moesin (yellow-

orange) $(b)$. In glomerular microaneurysms during anti-Thy1 disease (day 5), immunostaining for moesin/radixin (Texas Red-labeled) was very suggestive for localization in cellular extensions (arrowheads) $(c)$. This subcellular expression pattern of moesin was especially found in areas of glomerular remodeling during days 5 and 7 of anti-Thy1 disease $(c-f) . d$ demonstrates that moesin (FITC-green, nuclear counterstain in red) is frequently concentrated in the glomerular cell extensions (arrowhead). $e$ shows concentration of moesin (FITC-green, nuclear counterstain in red) in filopodia (arrowheads). While this subcellular distribution of moesin (FITC-green, large arrowheads) was frequently seen in $\alpha$-sm actin positive, activated MC, $\alpha$-sm actin (Texas red-red, small arrowheads) did not always colocalize with moesin to the cell extensions of the same cell (f). 

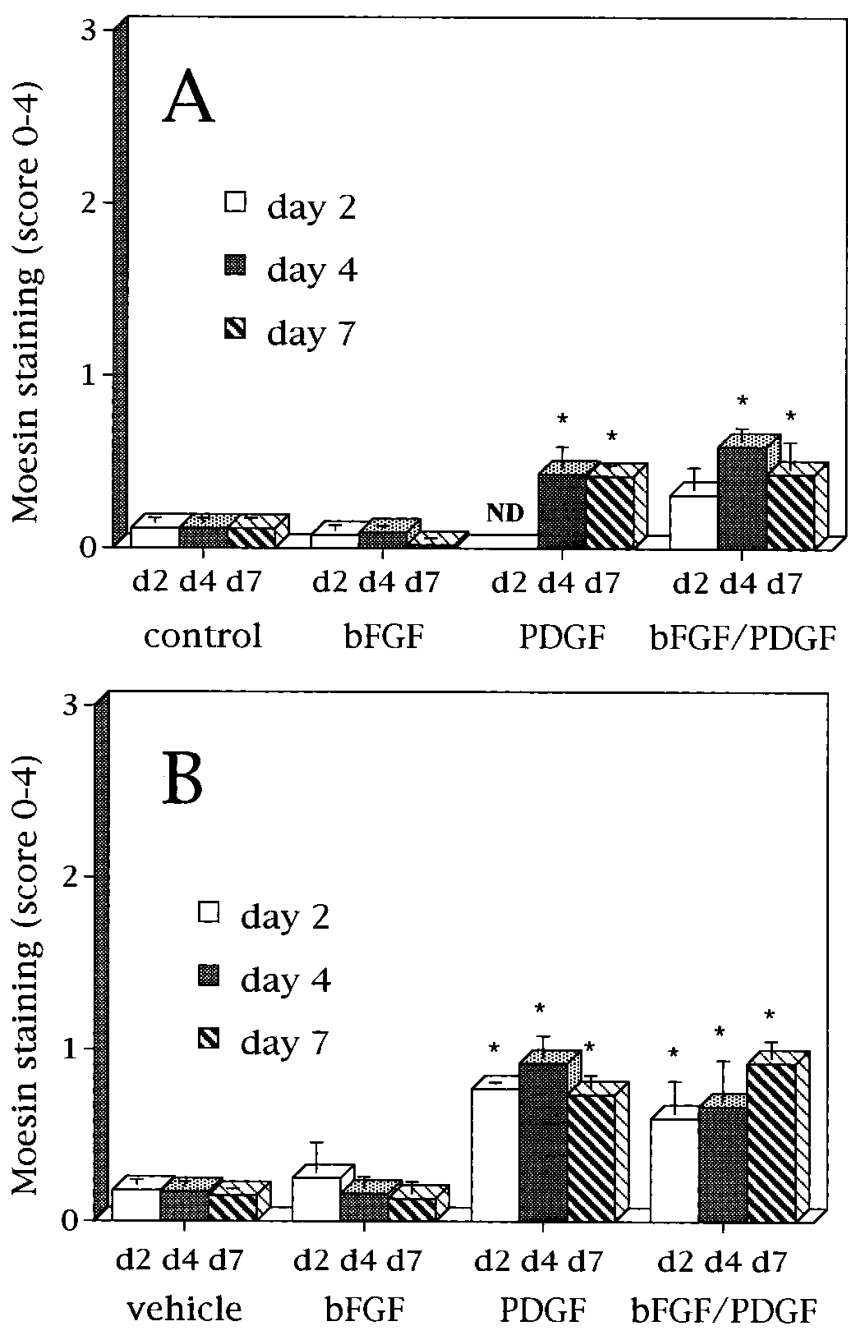

Figure 8. Quantification of glomerular immunostaining for moesin using pAsMo in normal rats (A) or "subnephritogenic" low dose antiThy1 treated rats $(B)$ after continuous infusion of equal molarities of either PDGF-BB or bFGF, or combined infusion of both PDGF-BB and bFGF for 2, 4, and $7 \mathrm{~d}$. Moesin staining was assessed semiquantitatively using a score from 0 to 4 (see Methods). Data are mean \pm SD. $* P<0.05$ versus corresponding vehicle-infused groups.

cell proliferation in these animals, expression of moesin was only increased by PDGF-BB, but not by bFGF infusion (Fig. 8 $B$ ). The infusion of both bFGF and PDGF-BB did not enhance the increase in moesin observed with PDGF alone. The effects of PDGF or bFGF infusion on radixin expression were identical to those observed with moesin (data not shown).

The effects of anti-PDGF or anti-bFGF antibody on moesin expression in the anti-Thy1 model were also examined. Anti-PDGF antibody treatment significantly reduced moesin expression at day 2 and day 4 in the anti-Thy1 model (Fig. 9 $A)$. In contrast, anti-bFGF antibody did not change the expression of moesin at all time points examined (days 2, 4, and 7) (Fig. 9 B). Similar findings were observed for radixin (data not shown).

\section{Discussion}

Moesin and radixin are recently discovered, widely distributed cytoskeletal proteins, which are thought to serve as links be-
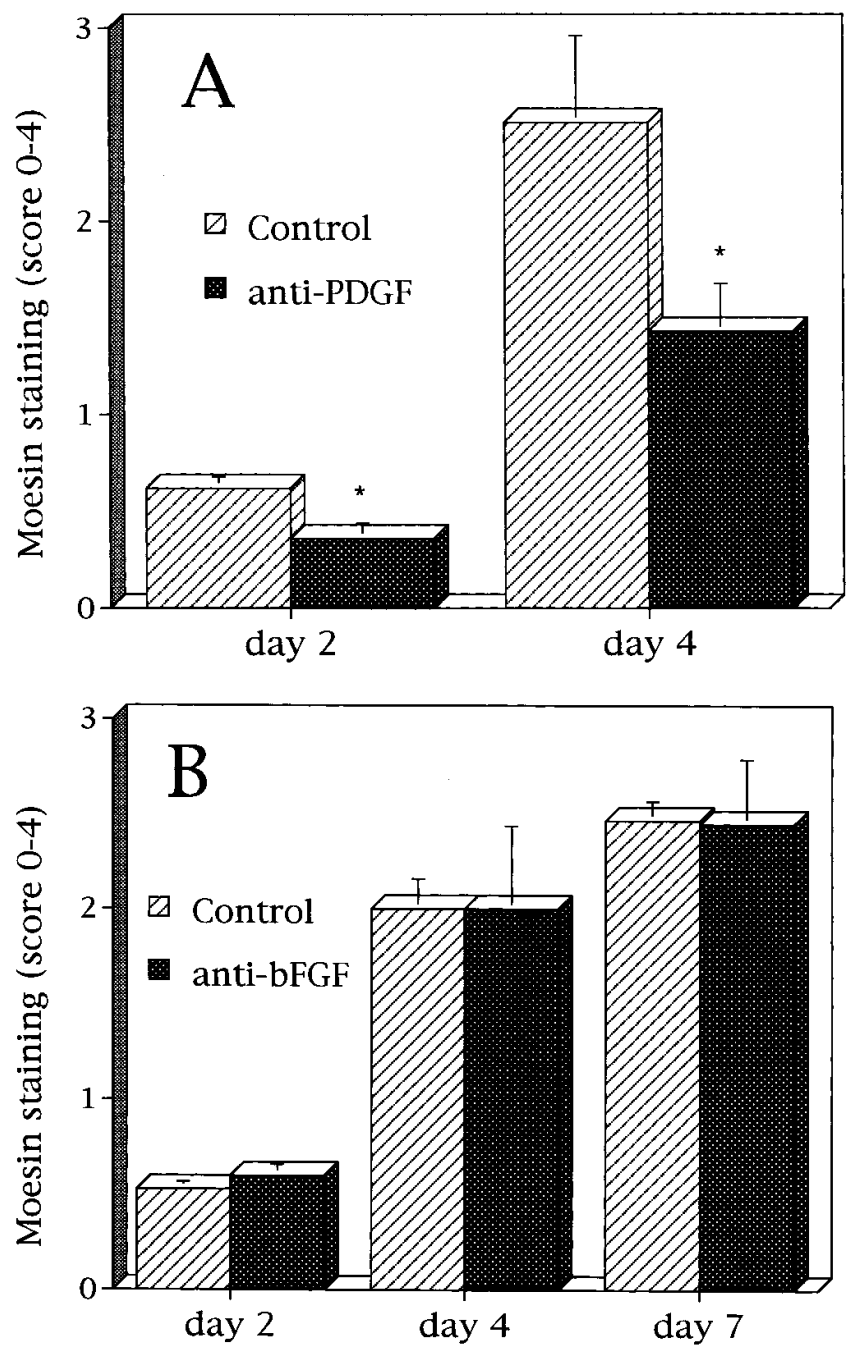

Figure 9. Glomerular moesin expression in anti-Thy1 disease after anti-PDGF $(A)$ or anti-bFGF antibody $(B)$ treatment. Inhibition of PDGF reduced moesin expression at day 2 and 4 significantly $(A)$. Anti-bFGF treatment did not reduce glomerular moesin expression at any time point examined $(A)$, despite its reduction of cell proliferation at day 4 (not shown). Data are mean \pm SD. $* P<0.01$ vs. control IgG infused group.

tween the plasma membrane and actin filaments (14). Moesin has been shown to be concentrated in specialized domains of the plasma membrane including microspikes, filopodia, and retraction fibers (13). These dynamic protrusions of the cell surface have been implicated to act as "sensory" devices for directional cell movement, for contact guidance, and also for the establishment of early cell-cell contacts in morphogenetic events such as neuronal growth and angiogenesis $(33,34)$. Despite the obvious importance of proliferation, cell migration, and coordinated cell-cell interaction in the process of remodeling and reconstitution of the glomerular architecture after injury, little is known about the expression of these proteins in vivo in normal and diseased states. We now report that moesin and radixin are dramatically increased in mesangial proliferative glomerulonephritis (anti-Thy1 model) and are highly expressed in cell extensions in glomerular areas undergoing remodeling. The increase of moesin and radixin was further shown to be PDGF, but not bFGF dependent. 
In the normal glomerulus, moesin and radixin are predominantly expressed by GEN, but also to a lesser extent by MC, parietal GEC and juxtaglomerular cells. Staining of podocytes could not be detected in vivo. Moesin and radixin mRNA and protein are also expressed in cultured MC, GEN, and visceral GEC. By immunostaining, the subcellular distribution of these proteins in cultured cells is very similar and dependent on the state of growth. Both proteins are cytoplasmic and in nonconfluent cultured MC and GEN localize primarily to perinuclear regions and to cell extensions such as filopodia (Fig. 1), while the staining pattern in confluent $\mathrm{MC}, \mathrm{GEN}$ and also visceral GEC is more confined to the plasma membrane. The expression of moesin and radixin in cultured visceral GEC with cobblestone appearance but not in podocytes in the normal rat glomerulus may reflect the advanced stage of dedifferentiation of podocyte-derived cobblestone cells in culture. Podocytes in vivo are terminally differentiated cells with a specific cell architecture and are unable to undergo cell division (35).

In experimental mesangial proliferative nephritis (antiThy1 model), a transient but marked increase of moesin and radixin protein was observed in glomeruli by immunostaining and was confirmed by Western blot analysis of isolated glomeruli. In the initial phase of mesangial injury (days 0-2), many infiltrating moesin- and radixin-positive macrophages were identified by double labeling with a macrophage-specific antibody (ED-1). Intraglomerular cells near the juxtaglomerular apparatus also stained positively for moesin and radixin. By day 5 radixin and moesin staining was substantially increased in a typical mesangial pattern, peaked on day 7 and was lower, but still significantly elevated on day 14 of anti-Thy 1 disease. Double labeling confirmed that most of these cells expressed $\alpha$-sm-actin, which is a marker of MC (4).

To determine if the increase in moesin and radixin protein in the anti-Thy1 model was due to an increase in mRNA levels, ISH for moesin and radixin mRNA was performed. Interestingly, ISH in two different experiments demonstrated a threefold increase on a per cell basis only in glomerular moesin mRNA, which peaked at days 3 to 4 . The lack of an increase in radixin mRNA and the observation that the peak in glomerular moesin mRNA by ISH preceded the peak in immunostaining by 3-4 d, suggests that other mechanisms may also regulate moesin and radixin expression, such as differences in protein turnover or efficiency of translation. Amieva et al. (13) reported that moesin protein redistributes from cytoplasmic areas to filopodia and microvilli in association with dynamic cell shape changes including protrusion and retraction. It is possible that the changes in intracellular localization associated with cell activation may also contribute to the changes in immunostaining and extractable protein from isolated glomeruli during disease.

The increased expression of moesin and radixin in the antiThy1 model was tightly correlated with the de novo expression of the cytoskeletal protein $\alpha$-sm-actin. In addition, cells expressing the $\alpha$-sm-actin could be shown to be moesin and radixin positive. Alpha smooth muscle actin, the principal actin isoform of vascular smooth muscle, is not normally expressed by mesangial cells in vivo, but is induced in different settings of mesangial cell injury (glomerulonephritis, hypertensive injury, reduction in renal mass) (36). Although the in vivo function of $\alpha$-sm actin expression in glomerular disease has not been defined, the expression of this actin isoform by $\mathrm{MC}$ in vivo is considered to be a phenotypic marker of myofibroblast-like, acti- vated MC (36). The observation by Pestonjamasp et al. (14) that moesin is an actin-binding protein suggests potential functional relationships.

Moesin and radixin were also highly expressed in cellular extensions within healing microaneurysms. In the anti-Thy1 model, mesangiolysis leads to ballooning of the glomerular capillaries with occasional microaneurysm formation (37). Despite microaneurysms being present in $7-8 \%$ of total glomeruli at days 5 to 7 , glomerular architecture is completely restored several weeks after disease induction. Regenerating glomerular cells (in the anti-Thy1 model mainly $\alpha$-sm actin positive, activated MCs, but also GEC and GEN) presumably migrate into these microaneurysms and may require higher levels of moesin and radixin to support the cellular activity during movement (Fig. $7 \mathrm{C}$ ). The increased expression of these cytoskeletal proteins in cellular extensions of elongated cells and in filopodia of activated $\mathrm{MC}$ was also frequently found in other areas of glomerular remodelling (Fig. 7, D-F). This subcellular distribution of moesin/radixin in cell extensions was relatively specific for these proteins, since $\alpha$-sm actin was not always colocalized to these cell extensions (Fig. $7 F$ ).

Another major finding was that the increased glomerular expression of moesin and radixin was dependent on PDGF, but not on bFGF. First, PDGF-infusion induced moesin/radixin expression in a mesangial pattern in normal rats and to a greater extent in rats primed with low dose ATS, while bFGFinfusion in the same experiments failed to induce expression of these cytoskeletal proteins. This specific induction by PDGF was not completely linked to its effect on MC proliferation, since bFGF, although to a lesser extent, also increased MC proliferation in low dose "subnephritogenic" anti-Thy1 rats (20). Second, anti-PDGF antibody treatment in anti-Thy1 disease reduced moesin/radixin expression significantly at day 2 and day 4 , while anti-bFGF antibody treatment did not affect moesin/radixin during the time course of disease (days 2, 4, and 7). This specific effect of anti-PDGF treatment on moesin/ radixin expression (seen already at day 2 ) could be dissociated from its effect on MC proliferation, since cellularity and the number of proliferating MC were only reduced at day 4 (18). In addition, anti-bFGF treatment, while also reducing $\mathrm{MC}$ proliferation at day 4 (19), had no effect on moesin or radixin expression.

The data on the regulation of moesin and radixin together with the time course of expression in anti-Thy1 disease do not completely rule out a role for these proteins in the proliferative response of $\mathrm{MC}$, but their involvement in other processes like migration merits consideration. PDGF has been shown to be a potent chemotactic factor for MC in culture (6), while no data are available for bFGF in this regard. In this study by Barnes, PDGF stimulated the migratory response of MC through a porous membrane in a dose dependent manner, with the MC showing extension and attachment of filopodia to the filter surface (6). In this context, PDGF may, in addition to its role in proliferation, mediate cytoskeletal changes (such as filopodia formation or cell shape change) via stimulation of moesin/radixin, which may be critical for cell adhesion and movement of MC.

In conclusion, moesin and radixin are constitutively expressed by all glomerular cell types except podocytes. In mesangial proliferative nephritis, an increase in moesin and radixin in $\alpha$-sm actin positive, activated MCs ("myofibroblasts") and in infiltrating macrophages was shown. Moesin and ra- 
dixin expression paralleled $\alpha$-sm actin expression by MC and followed the time course of cell proliferation, but persisted to day 14 despite resolution of cell proliferation by day 7 . The regulation of expression of these proteins occurs at the mRNA (moesin) and posttranscriptional (radixin and possibly moesin) level and its subcellular distribution is characterized by enrichment in filopodial cell extensions in areas of ongoing glomerular remodelling. The increased expression of moesin and radixin in the glomerulus was dependent on PDGF but not bFGF. These data suggest that a PDGF mediated increase in moesin and/or radixin may be important for MC migration/activation that accompanies the coordinated restoration of the glomerular architecture after MC injury.

\section{Acknowledgments}

The authors are grateful to Dr. Stephen Adler for providing the glomerular endothelial cell line, Dr. Russel Ross for providing the neutralizing anti-PDGF antibody, Dr. Michael Reidy for the gift of the neutralizing anti-bFGF antibody, and Dr. Juergen Floege for providing tissue of PDGF and bFGF infused rats. The authors also like to thank Dr. Stuart Shankland for his help in making computerized magnifications of images, Kimberlee Yeargen for her technical assistance, and all the workers of the "center" of photography of the University of Washington for their overall patience.

This work was supported in part by United States Public Health Service grants (DK-43422, DK-02142, HL-18645, AR-410452 to H. Furthmayr, and CA-09302 to M. Amieva), by a National Institutes of Health George O'Brien Kidney Center grant, and by a post-doctoral stipend of the Deutsche Forschungsgemeinschaft to Christian Hugo.

\section{References}

1. Couser, W.G. 1993. Pathogenesis of glomerulonephritis. Kidney Int. 44 (Suppl. 42):19-26.

2. Johnson, R.J. 1994. The glomerular response to injury: progression or resolution? Kidney Int. 45 (6):1769-1782.

3. Alpers, C.E., K.L. Hudkins, A.M. Gown, and R.J. Johnson. 1992. Enhanced expression of "muscle-specific" actin in glomerulonephritis. Kidney Int. 41 (5):1134-1142.

4. Johnson, R.J., H. Iida, C.E. Alpers, M.W. Majesky, S.M. Schwartz, P. Pritzl, K. Gordon, and A.M. Gown. 1991. Expression of smooth muscle cell phenotype by rat mesangial cells in immune complex nephritis. Alpha-smooth muscle actin is a marker of mesangial cell proliferation. J. Clin. Invest. 87 (3): $847-858$.

5. Barnes, J.L., K.A. Hevey, R.R. Hastings, and R.A. Bocanegra. 1994. Mesangial cell migration precedes proliferation in Habu snake venom-induced glomerular injury. Lab. Invest. 70 (4):460-467.

6. Barnes, J.L., and K.A. Hevey. 1990. Glomerular mesangial cell migration in response to platelet-derived growth factor. Lab. Invest. 62 (3):379-382.

7. Barnes, J.L., R.R. Hastings, and M.A. De La Garza. 1994. Sequential expression of cellular fibronectin by platelets, macrophages, and mesangial cells in proliferative glomerulonephritis. Am. J. Pathol. 145 (3):585-597.

8. Taraboletti, G., M. Morigi, M. Figliuzzi, R. Giavazzi, C. Zoja, and G. Remuzzi. 1992. Thrombospondin induces glomerular mesangial cell adhesion and migration. Lab. Invest. 67 (5):566-571.

9. Furthmayr, H., W. Lankes, and M. Amieva. 1992. Moesin, a new cytoskeletal protein and constituent of filopodia: its role in cellular functions. Kidney Int. 41 (3):665-670.

10. Cramer, L.P., T.J. Mitchison, and J.A. Theriot. 1994. Actin-dependent motile forces and cell motility. Curr. Opin. Cell Biol. 6:82-86.

11. Lankes, W.T., and H. Furthmayr. 1991. Moesin: a member of the protein 4.1-talin-ezrin family of proteins. Proc. Natl. Acad. Sci. USA. 88 (19):82978301.

12. Lankes, W.T., A.R. Schwartz, and H. Furthmayr. 1993. Cloning and sequencing of porcine moesin and radixin cDNA and identification of highly conserved domains. Biochim. Biophys. Acta. 1216 (3):479-482.

13. Amieva, M.R., and H. Furthmayr. 1995. Subcellular localization of moesin in dynamic filopodia, retraction fibers and other structures involved in substrate exploration, attachment and cell-cell contacts. Exp. Cell Research.
219 (1):180-196

14. Pestonjamasp, K., M.R. Amieva, C.P. Strassel, M. Nauseef, H. Furthmayr, and E.J. Luna. 1995. Moesin, ezrin, and p205 are actin-binding proteins associated with neutrophil plasma membranes. Mol. Biol. Cell. 6:247-259.

15. Takeuchi, K., N. Sato, H. Kasahara, N. Funayama, A. Nagafuchi, S. Yonemura, S. Tsukita, and S. Tsukita. 1994. Perturbation of cell adhesion and microvilli formation by antisense oligonucleotides to ERM family members. $J$. Cell Biol. 125 (6):1371-1384.

16. Franck, Z., R. Gary, and A. Bretscher. 1993. Moesin, like ezrin, colocalizes with actin in the cortical cytoskeleton in cultured cells, but its expression is more variable. J. Cell Sci. 105:219-231.

17. Duijvestijn, A.M., H. van Goor, F. Klatter, G.D. Majoor, E. van Bussel, and P.J. van Breda Vriesman. 1992. Antibodies defining rat endothelial cells: Reca-1, a pan-endothelial cell-specific monoclonal antibody. Lab. Invest. 66 (4): 459-466.

18. Johnson, R.J., E.W. Raines, J. Floege, A. Yoshimura, P. Pritzl, C. Alpers, and R. Ross. 1992. Inhibition of mesangial cell proliferation and matrix expansion in glomerulonephritis in the rat by antibody to platelet-derived growth factor. J. Exp. Med. 175 (5):1413-1416.

19. Floege, J., C. Hugo, M. Reilly, M. Burg, M. Reidy, W.G. Couser, and R.J. Johnson. 1995. Basic fibroblast growth factor (bFGF) mediates glomerular mesangial cell (MC) and endothelial cell (EC) proliferation in experimental mesangial proliferative nephritis (MesPGN). (abstract). J. Am. Soc. Nephrol. 6 : 865 .

20. Floege, J., E. Eng, B.A. Young, C.E. Alpers, T.B. Barrett, D.F. BowenPope, and R J. Johnson. 1993. Infusion of platelet-derived growth factor or basic fibroblast growth factor induces selective glomerular mesangial cell proliferation and matrix accumulation in rats. J. Clin. Invest. 92 (6):2952-2962.

21. Johnson, R., H. Yamabe, Y.P. Chen, C. Campbell, K. Gordon, P. Baker, D. Lovett, and W.G. Couser. 1992. Glomerular epithelial cells secrete a glomerular basement membrane-degrading metalloproteinase. J. Am. Soc. Nephrol. 2 (9):1388-1397.

22. Adler, S., P.J. Baker, R.J. Johnson, R.F. Ochi, P. Pritzl, and W.G Couser. 1986. Complement membrane attack complex stimulates production of reactive oxygen metabolites by cultured rat mesangial cells. J. Clin. Invest. 77 (3):762-767.

23. Adler, S., and B. Eng. 1993. Integrin receptors and function on cultured glomerular endothelial cells. Kidney Int. 44:278-284.

24. Johnson, R.J., P. Pritzl, H. Iida, and C.E. Alpers. 1991. Platelet-complement interactions in mesangial proliferative nephritis in the rat. Am. J. Pathol. 138 (2):313-321.

25. Lindner, V., and M. A. Reidy. 1991. Proliferation of smooth muscle cells after vascular injury is inhibited by an antibody against basic fibroblast growth factor. Proc. Natl. Acad. Sci. USA. 88 (9):3739-3743.

26. Lankes, W., A. Griesmacher, J. Gruenwald, R. Schwartz-Albiez, and R. Keller. 1988. A heparin-binding protein involved in inhibition of smooth-muscle cell proliferation. Eur. Biochem. J. 251:831-842.

27. Floege, J., C.E. Alpers, E.H. Sage, P. Pritzl, K. Gordon, R.J. Johnson, and W.G. Couser. 1992. Markers of complement-dependent and complementindependent glomerular visceral epithelial cell injury in vivo. Expression of antiadhesive proteins and cytoskeletal changes. Lab. Invest. 67 (4):486-497.

28. Skalli, O., P. Ropraz, A. Trzeciak, G. Benzonana, D. Gillessen, and G. Gabbiani. 1986. A monoclonal antibody against alpha-smooth muscle actin: a new probe for smooth muscle cell differentiation. J. Cell Biol. 103 (6):27872796.

29. Floege, J., E. Eng, B.A. Young, W.G. Couser, and R.J. Johnson. 1993. Heparin suppresses mesangial cell proliferation and matrix expansion in experimental mesangioproliferative glomerulonephritis. Kidney Int. 43 (2):369-380.

30. Hugo, C., R. Pichler, R. Meek, K. Gordon, T. Kyriakides, J. Floege, P. Bornstein, W. Couser, and R.J. Johnson. 1995. Thrombospondin1 is expressed by proliferating mesangial cells in vivo and is upregulated by PDGF and bFGF. Kidney Int. 48:1846-1856.

31. Laemmli, U.K. 1970. Cleavage of structural proteins during the assembly of the head of bacteriophage T4. Nature (Lond.). 227 (259):680-685

32. Wilcox, J.N., K.M. Smith, S.M. Schwartz, and D. Gordon. 1989. Localization of tissue factor in the normal vessel wall and in the atherosclerotic plaque. Proc. Natl. Acad. Sci. USA. 86:2839-2843.

33. Robinson, J.M., and M.J. Karnovsky. 1980. Specializations in filopodial membrane at points of attachment to the substrate. J. Cell Biol. 87:562-568.

34. Heidemann, S.R., P. Lamoureux, and R.E. Buxbaum. 1990. Growth cone behavior and production of traction force. J. Cell Biol. 111:1949-1957.

35. Mundel, P., J. Reiser, and W. Kriz. 1995. Differentiation of rat podocytes in vitro (abstract). J. Am. Soc. Nephrol. 6:878.

36. Johnson, R.J., J. Floege, A. Yoshimura, H. Iida, W.G. Couser, and C.E. Alpers. 1992. The activated mesangial cell: a glomerular "myofibroblast"? J. Am. Soc. Nephrol. 2:190-197.

37. Iruela-Arispe, L., K. Gordon, C. Hugo, A.M. Duijvestijn, K.P. Claffey, M. Reilly, W.G. Couser, C.E. Alpers, and R.J. Johnson. 1995. Participation of glomerular endothelial cell in the capillary repair of glomerulonephritis. Am. J. Path. 147:1715-1727. 